\title{
Desain Pengendalian Koordinat Gerak Robot Nirkabel Cerdas Menggunakan Aplikasi Android Melalui Akselerasi Gerakan Smartphone
}

\author{
Yoga Alif Kurnia Utama ${ }^{1}$, Arief Budijanto ${ }^{2}$, Aditya K. S. ${ }^{3}$ \\ Jurusan Teknik Elektro Universitas Widya Kartika, Surabaya \\ J1. Sutorejo Prima Utara II No.1 Surabaya 60112 \\ ${ }^{1}$ yoga.alif@widyakartika.ac.id \\ ${ }^{2}$ ariefbudijanto@widyakartika.ac.id \\ adityaks601@gmail.com
}

Intisari - Perkembangan teknologi saat ini banyak mengarah kepada dunia robotika. Saat ini robot menjadi alat bantu untuk menyelesaikan pekerjaan manusia sehari-hari. Peranan robot juga sudah mulai mengganti peran manusia dalam dunia industri seperti pada industri mobil, sepeda motor, dan lain-lain. Oleh karena itu tidak heran, penelitian mengenai robot, semakin lama semakin bertambah. Banyak sekali jenis robot yang telah diciptakan oleh manusia, seperti robot manipulator atau yang biasa disebut robot lengan yang banyak diaplikasikan untuk membawa barang. Ada pula robot humanoid, yang merupakan robot berbentuk manusia, yang saat ini telah dikembangkan untuk membawa orang sakit, dan mobile robot yang sekarang banyak digunakan untuk menjelajah suatu daerah. Dalam beberapa penelitian robot saat ini, penggunaan teknologi mobile robot sebagai robot penjelajah menjadi fokus utama peneliti. Sistem navigasi pada mobile robot merupakan salah satu permasalahan yang sering dihadapi. Oleh karena itu, penelitian ini mencoba untuk mengembangkan suatu cara pengendalian navigasi robot untuk bergerak pada suatu koordinat tertentu dengan menggunakan aplikasi android pada smartphone. Dari hasil pengujian yang telah dilakukan dapat dilihat bahwa rata-rata eror yang telah terjadi selama pergerakan pada sumbu $x$ adalah $0.27 \mathrm{~cm}$ sedangkan pada sumbu y adalah $0.28 \mathrm{~cm}$ dimana pergerakan robot ini menggunakan bluetooth dengan baudrate sebesar 57600 bps.

Kata kunci - Accelerometer, Android, Arduino, Bluetooth, Robot

Abstract - Today, development of technology leads to the world of robotics. Currently the robot is a tool to complete the daily work of man. The role of robots has also begun to replace human roles in the industrial world such as in the car industry, motorcycles, and the others. Therefore, it is not surprisingly, research on robots was increased. There are many of types of robots that have been created by humans, such as robot manipulators or commonly called arm robots that are widely applied to carry goods. There is also a humanoid robot, which is a human-shaped robot, which has been developed to bring sick people, and mobile robots are widely used to explore some areas. In recent robotic studies, the mobile robot technology uses as an exploratory robot is the main focus of the researcher. Navigation system in mobile robot is one of the problems that often faced. Therefore, this research tries to develop a way of controlling the navigation of robots to move on a certain coordinate by using android applications on smartphones. From the results of tests that have been done can be seen that the average error that has occurred during the movement on the $\mathrm{x}$ axis is $0.27 \mathrm{~cm}$ while on the $\mathrm{y}$-axis is $0.28 \mathrm{~cm}$ where the movement of this robot using bluetooth with baudrate of $57600 \mathrm{bps}$. Keywords - Accelerometer, Android, Arduino, Bluetooth, Robot

\section{PENDAHULUAN}

Robot merupakan sebuah perangkat mekanik yang memiliki rangkaian elektronik di dalamnya dan dapat dikendalikan melalui perangkat lunak untuk menghasilkan suatu gerakan [1]. Dalam perkembangan teknologi pada zaman sekarang, robot banyak digunakan untuk membantu manusia dalam kehidupan sehari-hari baik dalam lingkungan rumah tangga maupun dalam lingkungan industri. Robot ini dapat membuat beberapa pekerjaan dapat diselesaikan dengan cepat, efektif, dan efisien. Sebagai contoh dalam Volume 12, No. 1, Januari 2018 sistem otomatisasi pada industri seperti sekarang ini.

Tidak hanya ilmu robotika yang berkembang, sistem elektronika pada robot juga mengalami perkembangan dalam beberapa dekade terakhir ini. Dari mulai menggunakan rangkaian transistor sederhana menjadi suatu chip yang terintegrasi yang disebut microcontroller.

Microcontroller sebagai suatu terobosan teknologi mikroprosesor dan mikrokomputer, yang memiliki kandungan transistor yang sangat banyak namun hanya membutuhkan ruang yang kecil, sehingga bisa 
meminimalisir penggunaan komponen elektronika. Selain itu chip ini juga dapat diprogram menggunakan komputer. Hal ini akan semakin mempermudah dalam pengembangan robot yang ingin dibuat.

Dalam mencapai kemajuan teknologi robot tersebut, maka banyak sekali penelitian yang sudah dilakukan. Ada penelitian mengenai robot manipulator [2], robot humanoid [3], dan juga mobile robot [4]. Pada mobile robot yang biasa dipakai sebagai robot penjelajah, sistem navigasi sering sekali menjadi fokus perhatian utama dalam sebuah penelitian. Kendali navigasi pergerakan robot dan waktu yang dibutuhkan untuk menuju ke sebuah lokasi tertentu saat ini merupakan salah satu permasalahan yang sering dihadapi dalam pengembangan mobile robot.

Jika mobile robot digunakan untuk menjangkau tempat-tempat yang berbahaya maka navigasi tanpa kabel mutlak dibutuhkan. Oleh karena itu, penelitian ini mencoba untuk mengaplikasikan teknologi navigasi robot tanpa menggunakan kabel dimana navigasi robot tersebut diatur menggunakan aplikasi android pada smartphone. Dari penelitian ini dapat dilihat bahwa aplikasi android dapat mampu menggerakkan sebuah robot dalam koordinat tertentu.

\section{METODE}

Metode perancangan dan analisis sistem pada penelitian ini secara garis besar dibagi menjadi dua bagian utama, yaitu perencanaan perangkat keras dan perencanaan perangkat lunak. Adapun tujuan dari perencanaan tersebut adalah untuk menghasilkan sistem robot yang dapat bergerak sesuai dengan keinginan pengguna melalui aplikasi pada smartphone. Sebelum mendesain perencanaan perangkat keras dan perangkat lunak maka perlu diketahui terlebih dahulu bagianbagian dari sistem robot atau diagram blok sistem tersebut. Hal ini dilakukan juga untuk menghindari kegagalan pada pergerakan dan pengendalian sistem saat diaplikasikan nanti. Diagram blok sistem ditunjukan pada Gbr 1 di bawah ini. Pada gambar tersebut tampak bahwa sistem ini menggunakan sensor accelerometer pada perangkat android yang dipancarkan melalui gelombang bluetooth pada frekuensi 2.4
Ghz, dimana pada saat bluetooth memancarkan sinyal maka data langsung diterima oleh arduino uno melalui perangkat komunikasi modul bluetooth HC-05 yang kemudian data tersebut akan diproses untuk menggerakkan motor DC. Motor DC digunakan sebagai tenaga penggerak pada robot cerdas tersebut. Selama terjadi pergerakan robot tersebut, rotary encoder akan menghitung jarak robot yang telah ditempuh dan akan berhenti setelah mencapai nilai tertentu.

Prinsip yang digunakan adalah prinsip komunikasi data nirkabel yang mana data yang dikirim adalah data pada activity sensor change atau aktivitas perubahan nilai pada sensor accelerometer sehingga nilai akselerasi yang dinamis itu yang akan dikonversi menjadi nilai yang akan menjadi koordinat yang nantinya akan diteruskan ke arduino.

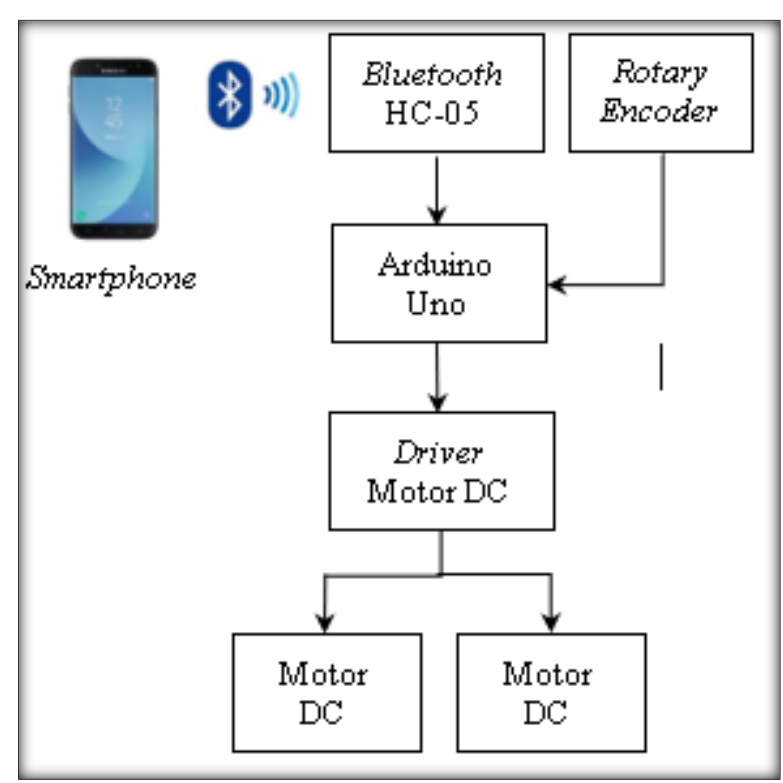

Gbr 1. Diagram Blok Sistem

Setelah mengetahui blok diagram sistem maka langkah selanjutnya adalah melakukan perancangan sistem perangkat keras dan perangkat lunak robot.

\section{A. Perancangan Perangkat Keras (Hardware)}

Perancangan perangkat keras meliputi, rangkaian driver motor DC menggunakan IC L293, bluetooth HC-05, rotary encoder, dan rangkaian controller menggunakan arduino uno. Bagian-bagian komponen tersebut dijabarkan sebagai berikut: 


\section{1) Motor $D C$}

Motor DC berfungsi sebagai alat penggerak utama pada robot ini. Motor DC ini akan membuat robot bergerak ke depan dan ke belakang serta belok kiri maupun belok kanan. Karena fungsinya tersebut, maka motor DC ini akan diletakkan pada roda belakang robot kanan dan kiri. Oleh karena itu, robot ini membutuhkan 2 motor DC sebagai tenaga penggeraknya.

Motor DC yang digunakan memiliki gear box dengan perbandingan $48: 1$ dengan tegangan motor sebesar $9 \mathrm{~V}$. Motor ini memiliki kecepatan $100 \mathrm{rpm}-240 \mathrm{rpm}$ dengan arus motor sebesar $100 \mathrm{~mA}-120 \mathrm{~mA}$. Motor ini juga dilengkapi dengan roda plastik dengan diameter sebesar 66 mm dengan ban karet. Motor DC yang digunakan pada robot ini dapat dilihat pada Gbr 2.Dalam menggunakan motor DC ini, diperlukan sebuah rangkaian driver motor DC [5]. Driver motor DC ini menggunakan IC L293 dimana IC ini dapat digunakan untuk menggerakkan 2 motor DC sekaligus. Skema rangkaian driver motor DC dan koneksinya dengan kontroler arduino uno dapat dilihat pada Gbr 6 .

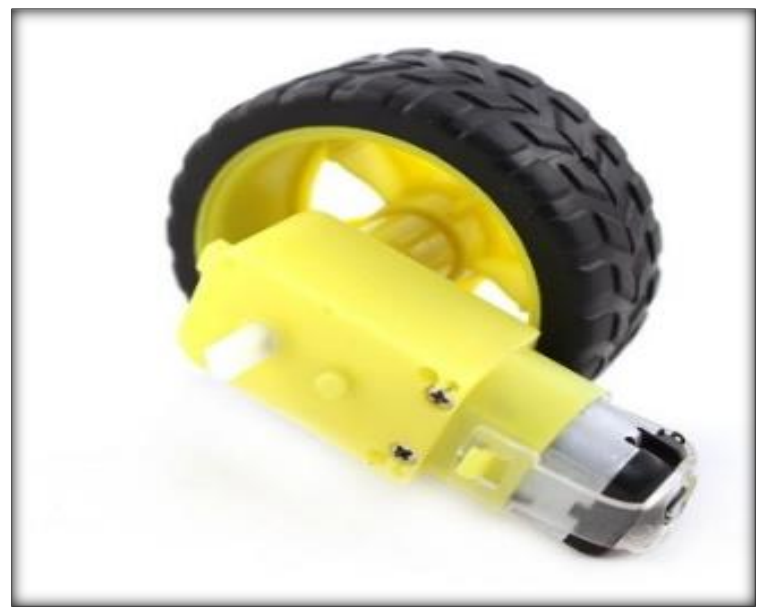

Gbr 2. Motor DC

2) Bluetooth

Rangkaian bluetooth yang dipakai pada robot ini menggunakan modul bluetooth bertipe HC-05 yang bersifat ready to use yang banyak dijual di pasaran. Bluetooth bertipe HC-05 ini dapat dilihat pada Gbr 3. Tipe bluetooth ini terdiri dari pin VCC, GND, TX, dan RX [6]. Pin VCC selalu dikoneksikan dengan tegangan 5 Volt, sedangkan pin GND selalu dikoneksikan dengan ground. Selain itu, pin RX berfungsi untuk menerima data yang dikirimkan dari smartphone ke arduino uno dan pin TX berfungsi mengirimkan data yang berasal dari arduino uno ke smartphone.

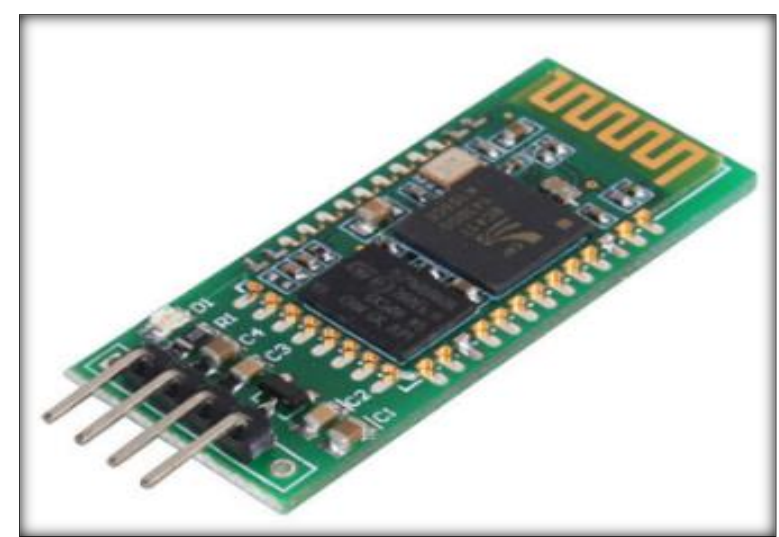

Gbr 3. Bluetooth HC-05

\section{3) Arduino Uno}

Arduino uno merupakan papan pengembangan (development board) mikrokontroler yang berbasis IC ATmega328P [7]. Modul Arduino yang digunakan pada sistem robot ini, dapat dilihat pada Gbr 4. Pada sistem ini, arduino digunakan sebagai kontroler robot. Kontroler ini memiliki beberapa fungsi, yaitu pertama, sebagai menerima data dari smartphone melalui bluetooth HC-05. Data ini merupakan koordinat yang harus ditempuh oleh robot. Arduino akan memproses data tersebut yang kemudian akan digunakan untuk mengerakkan robot ke segala arah, baik bergerak maju, mundur, belok kanan atau belok kiri. Arduino uno memiliki 14 digital pin input / output (atau biasa ditulis $\mathrm{I} / \mathrm{O}$, dimana 6 pin diantaranya dapat digunakan sebagai output PWM), 6 pin input analog, menggunakan crystal $16 \mathrm{MHz}$, koneksi USB, jack listrik, header ICSP dan tombol reset. Dari kesemua pin-pin arduino uno tersebut, beberapa pin digunakan untuk dikoneksikan ke komponen pembentuk sistem robot ini, yaitu, driver motor DC dan rotary encoder untuk pergerakan robot, kemudian bluetooth yang digunakan untuk berkomunikasi dengan smartphone.Koneksi komponenkomponen tersebut terhadap modul arduino uno dapat dilihat pada Gbr 6 .

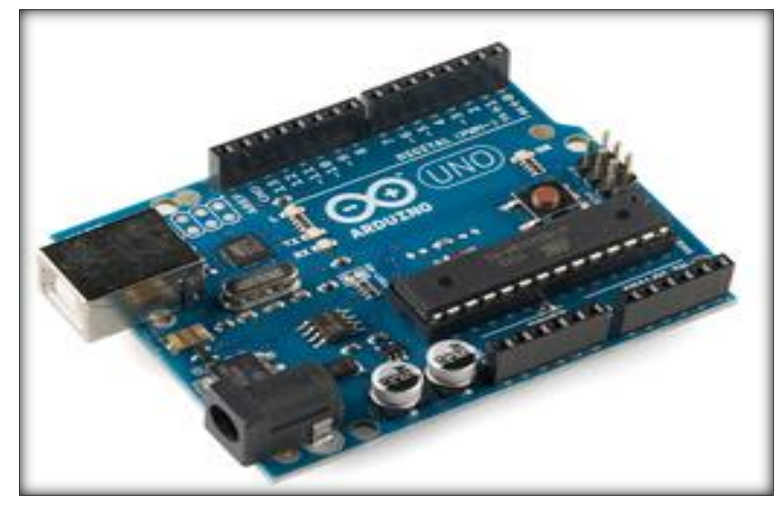

Gbr 4. Arduino Uno 


\section{4) Rotary Encoder}

Rotary Encoder ini berfungsi untuk menghitung jarak yang talah ditempuh oleh robot. Sensor ini terdiri dari piringan berlubang dengan jumlah 100 lubang dengan optocoupler bentuk $\mathrm{u}$ di dalamnya. Prinsip dasar rotary encoder ini adalah ketika roda robot bergerak dan sensor optocoupler menyentuh lubang maka optotransistor akan terkena cahaya, sehingga logika yang dihasilkan adalah HIGH.

Begitu pula sebaliknya, ketika roda robot bergerak dan sensor optocoupler terhalang maka optotransistor tidak terkena cahaya, sehingga logika yang dihasilkan adalah LOW [8]. Pergerakan logika HIGH menjadi LOW ini yang akan dibaca oleh controller. Bentuk sensor rotary encoder ini dapat dilihat pada Gbr 5, sedangkan koneksinya terhadap arduino uno dapat dilihat pada Gbr 6.

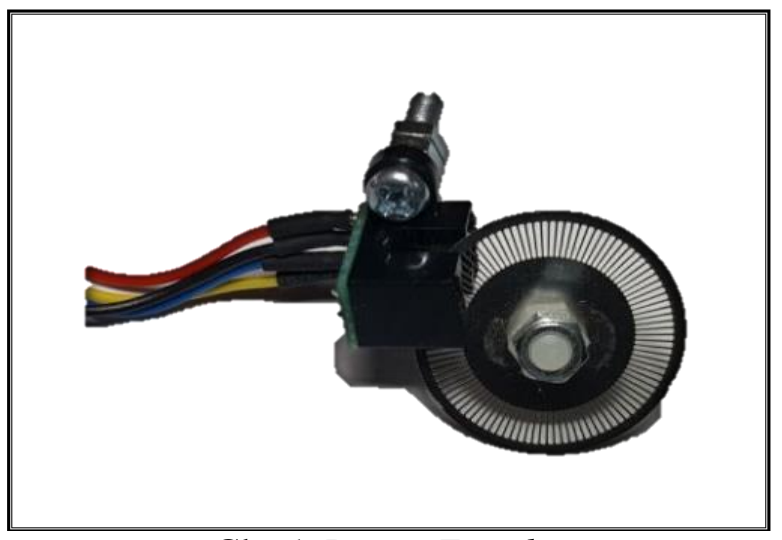

Gbr 5. Rotary Encoder

Komponen-komponen yang telah dijabarkan sebelumnya dikoneksikan ke arduino uno. Skematik rangkaian tersebut dapat dilihat pada Gbr 6.

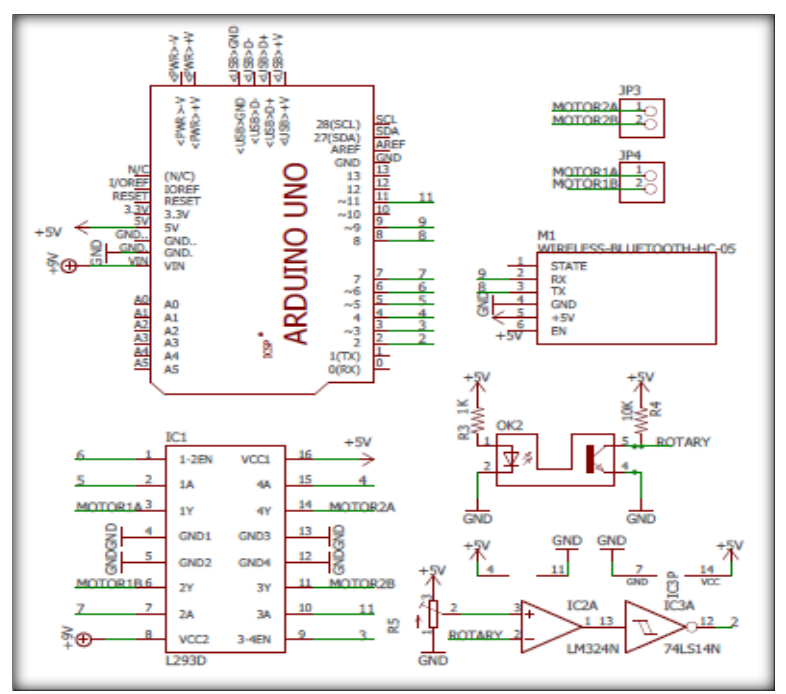

Gbr 6. Skematik Rangkaian
Dari Gambar 6 dapat dilihat bahwa, sistem ini memerlukan 9 pin arduino uno yang mana terdiri dari 6 pin output, 2 pin Serial, dan 1 pin Interrupt. Enam pin output digunakan untuk mengendalikan arah putaran motor DC untuk melakukan gerakan. Enam pin ini langsung terhubung ke IC L293 Driver Motor DC. Pada IC L293, pin 16 sebagai Vcc mendapat supply tegangan 5 volt langsung dari arduino uno, sedangkan tegangan referensi (Vref) pada kaki pin 8 didapat dari penambahan baterai tipe $6 \mathrm{~F} 22$ sebesar 9 volt. Kemudian untuk pergerakan robot dikontrol melalui pin 2, 7, 10, 15 dimana masingmasing menjalankan fungsinya untuk bisa melakukan instruksi maju dan mundur. Pin 2 pada IC terhubung ke output pin 5 arduino uno R3, pin 7 pada IC masuk ke pin 7 arduino uno $\mathrm{R} 3$, pin 10 pada IC masuk ke pin 11 pada arduino uno R3, dan pin 15 pada IC driver masuk ke pin 4 pada arduino uno R3. Fungsi pin 1 dan pin 9 (EN1 dan EN2) pada IC driver berfungsi untuk mengaktifkan atau menonaktifkan rangkaian driver tersebut, dimana keduanya terhubung pada pin 6 dan pin 3 arduino uno R3.

Kemudian untuk pin Serial digunakan untuk melakukan koneksi dengan Smartphone melalui modul bluetooth HC-05. Pin Serial ini terdiri dari pin TX dan RX yang mana terhubung pada pin 8 dan pin 9 arduino uno R3. Pin yang terakhir yang digunakan adalah pin 2 dimana pin ini merupakan pin Interrupt. Pin ini akan diset dengan mode falling edge. Mode ini dimaksudkan agar suatu program tertentu berjalan ketika nilai logika pada pin tersebut bergerak/jatuh dari nilai logika $\mathrm{HIGH}$ menuju logika LOW.

\section{B. Perancangan Perangkat Lunak (Software)}

Perangkat lunak yang digunakan dalam pembuatan robot ini adalah bahasa pemrograman $\mathrm{C}++$ yang ditulis pada software Arduino IDE serta pemrograman melalui software MIT App Inventor. Dalam pembuatan robot cerdas yang digerakkan atau dikendalikan melalui smartphone ini, kunci utama terletak pada kinerja sensor accelerometer pada perangkat seluler dan proses komunikasi antara perangkat seluler dengan modul bluetooth yang terpasang di bagian robot ini. Pembuatan program yang akan diisi ke dalam IC Atmega 328 pada arduino uno di sistem robot ini, akan mengacu pada diagram alir atau flowchart yang ditunjukkan pada Gbr 7 di bawah ini. 


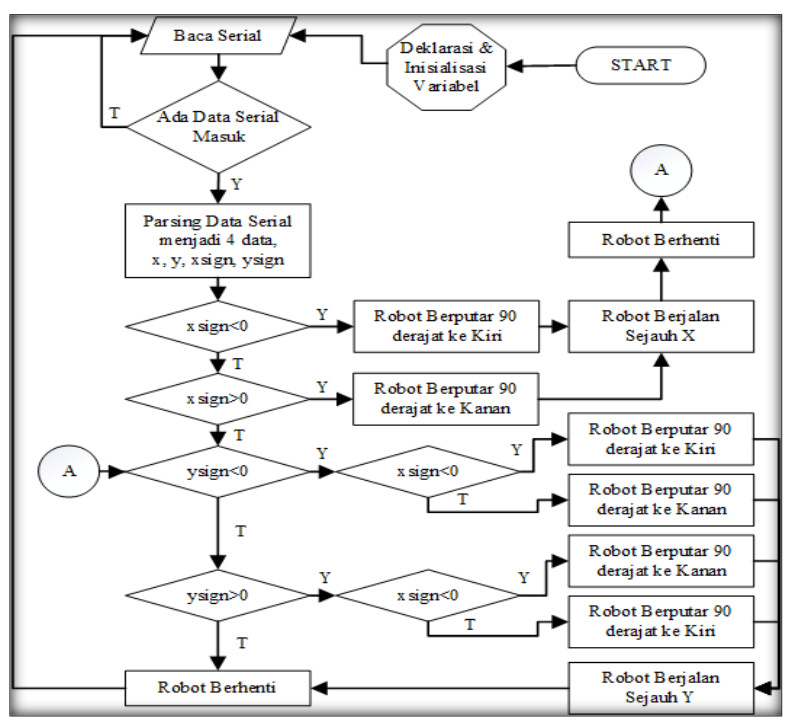

Gbr 7. Flowchart Program Utama pada Arduino Uno

Program ini berjalan dengan posisi awal robot dianggap pada koordinat $(0,0)$ dan robot mengarah ke sumbu y positif seperti ditunjukkan pada Gbr 8.

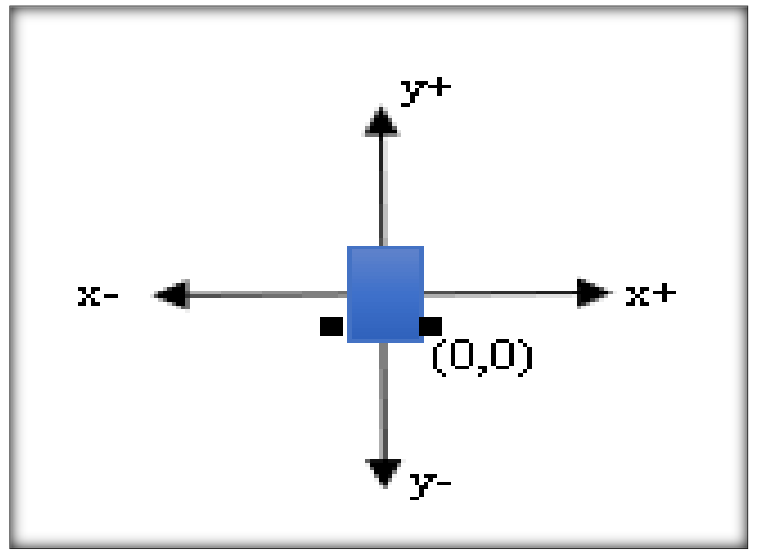

Gbr 8. Posisi Awal Robot

Program ini terlebih dahulu akan membaca apakah ada data serial yang masuk melalui bluetooth. Jika ada data maka lakukan parsing data sehingga mendapat 4 data yang diletakkan di 4 variabel yang berbeda yaitu $\mathrm{x}, \mathrm{y}$, xsign, ysign, dimana $\mathrm{x}$ adalah jarak yang harus ditempuh robot dalam sumbu $\mathrm{x}$, $\mathrm{y}$ adalah jarak yang harus ditempuh robot dalam sumbu $\mathrm{y}$, xsign adalah arah pergerakan robot pada sumbu x (jika bernilai negatif, arah robot ke kiri, jika bernilai positif, arah robot ke kanan), sedangkan ysign adalah arah pergerakan robot pada sumbu y (jika bernilai negatif, arah robot ke bawah, jika bernilai positif, arah robot ke atas). Selanjutnya, arah robot akan mengikuti nilai dari dari data yang diterima. Sebagai contoh jika robot menerima data xsign=-
$1, \mathrm{x}=3$,ysign $=1, \mathrm{y}=2$, maka robot akan terlebih dahulu berputar $90^{\circ}$ ke kiri kemudian berjalan sejauh $3 \mathrm{~cm}$ kemudian berputar $90^{\circ}$ ke kanan kemudian berjalan sejauh $2 \mathrm{~cm}$ lalu berhenti. Selanjutnya robot akan membaca lagi data serial yang masuk, begitu seterusnya.Kemudian, untuk pembuatan program aplikasi android pada smartphone, mengacu pada diagram alir atau seperti yang ditunjukkan pada Gbr 9 .

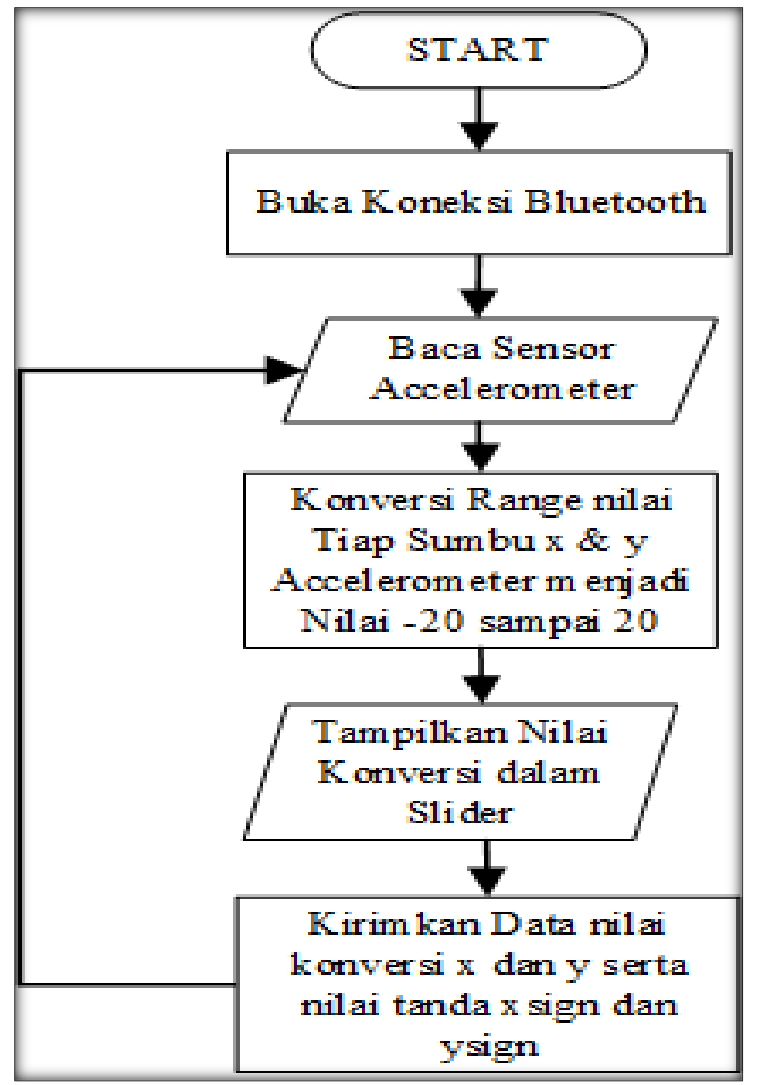

Gbr 9. Flowchart Program Android

Dari Gambar 9 dapat dilihat bahwa program dimulai dengan membuka koneksi bluetooth agar bisa berkomunikasi dengan robot. Setelah itu membaca nilai accelerometer yang ada pada smartphone.

\section{HASIL DAN PEMBAHASAN}

Setelah melakukan desain perancangan dan pembuatan sistem robot, maka tahap selanjutnya adalah melakukan serangkaian uji coba. Uji coba dilakukan di Laboratorium Teknik Elektro Universitas Widya Kartika Surabaya. Uji coba dilakukan terhadap sistem robot yang sudah dibuat, yang ditunjukkan pada Gbr 10. 


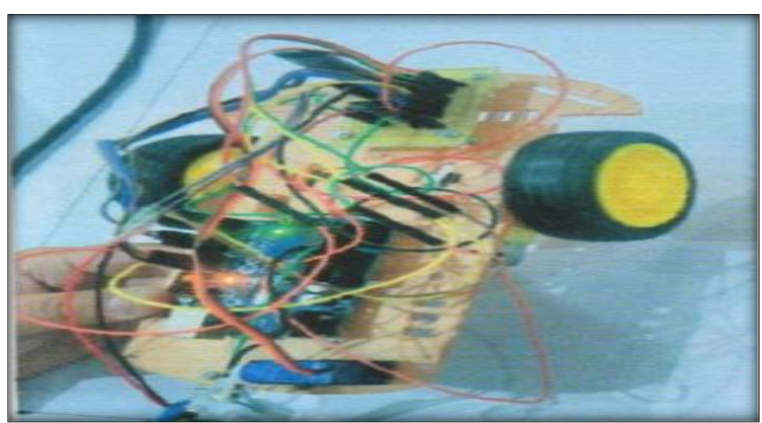

Gbr 10. Robot Nirkabel Cerdas

Konstruksi dari robot ini menggunakan papan akrilik yang telah melalui proses laser cutting dengan ukuran panjang keseluruhan $25 \mathrm{~cm}$ dan lebar $10 \mathrm{~cm}$. Akrilik dipilih karena bahan ini mempunyai bobot yang ringan namun mempunyai kekuatan yang baik dan juga mudah untuk dilakukan modifikasi semisal menambahkan lubang mur, baut, dan sebagainya, jika dibandingkan dengan bahan yang lain. Kemudian, untuk menggerakkan robot tersebut maka diperlukan software android yang terpasang pada sebuah smartphone. Saat uji coba ini berlangsung, smartphone yang dipakai adalah smartphone dengan tipe Lenovo A7000 Plus. Program yang telah dibuat yang mana digunakan dalam uji coba pergerakan robot ini dapat dilihat pada Gbr 11.

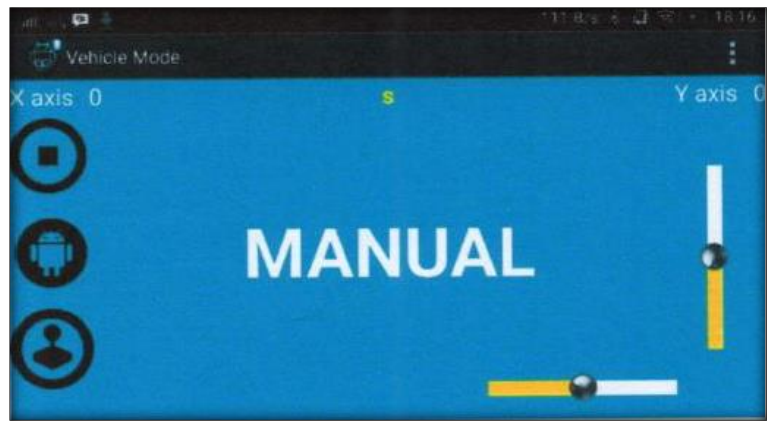

Gbr 11. Display Aplikasi Android

Pertama, uji coba dilakukan untuk mengetahui kinerja komunikasi antara bluetooth HC-05 dengan smartphone. Uji coba ini dilakukan dengan menentukan nilai baudrate yang tepat agar komunikasi data dapat terjadi secara real time. Hal ini sangat penting dilakukan agar pergerakan robot dapat lancar tanpa tersendat. Hasil uji coba yang telah dilakukan dapat dilihat pada Tabel 1 di bawah ini. Pada saat baud rate bluetooth dinilai 9600 bps, robot dapat berjalan baik namun masih tersendat. Hal ini dikarenakan masih adanya delay antara gerakan smartphone dengan penerimaan data yang diterima robot. Pada saat baud rate bluetooth dinaikkan ke level 57600 bps, nilai koordinat yang dikirim dari smartphone dapat diterima oleh robot secara real time.

Tabel 1. Hasil Percobaan Penentuan Baudrate

\begin{tabular}{|c|c|c|c|c|c|c|c|}
\hline No & Baud & \multicolumn{6}{|c|}{ Gerakan Robot } \\
\cline { 3 - 8 } & $\begin{array}{c}\text { Rate } \\
\text { (bps })\end{array}$ & $\begin{array}{c}\text { M } \\
\text { F }\end{array}$ & $\begin{array}{c}\text { M } \\
\text { B }\end{array}$ & FR & FL & BR & BL \\
\hline 1 & 9600 & Ok & $\begin{array}{c}\text { Ok } \\
\text { s }\end{array}$ & Ok & $\begin{array}{c}\text { Ok } \\
\text { s }\end{array}$ & $\begin{array}{c}\text { Ok } \\
\text { s }\end{array}$ & No \\
\hline 2 & 14400 & No & No & No & No & No & No \\
\hline 3 & 19200 & No & No & No & No & No & No \\
\hline 4 & 57600 & Ok & Ok & Ok & Ok & Ok & Ok \\
\hline 5 & $\begin{array}{c}11520 \\
0\end{array}$ & $\begin{array}{c}\text { Ok } \\
\text { s }\end{array}$ & $\begin{array}{c}\text { Ok } \\
\text { s }\end{array}$ & $\begin{array}{c}\text { Ok } \\
\text { s }\end{array}$ & $\begin{array}{c}\text { Ok } \\
\text { s }\end{array}$ & $\begin{array}{c}\text { Ok } \\
\text { s }\end{array}$ & $\begin{array}{c}\text { Ok } \\
\text { s }\end{array}$ \\
\hline
\end{tabular}

Keterangan:

MF : Move Forward / maju lurus

MB : Move Back/ jalan mundur

FR : Front Right / belok kanan-maju

FL : Front Left / belok kiri-maju

BR : Back Right / belok kanan-mundur

BL : Back Left / belok kiri-mundur

Ok : Berjalan baik

Oks : Berjalan tersendat

No : Tidak jalan

Setelah itu, uji coba selanjutnya adalah robot akan bergerak pada suatu koordinat tertentu dengan menggunakan pergerakan dari smartphone. Data posisi referensi dan posisi aktual yang dicapai robot dapat dilihat pada Tabel 2. 
Tabel 2. Hasil Percobaan Posisi Robot

\begin{tabular}{|c|c|c|c|c|c|c|c|}
\hline \multirow{2}{*}{$\begin{array}{l}\text { Arah } \\
\text { Ro-bot }\end{array}$} & \multirow{2}{*}{$\begin{array}{l}\text { Sudut Kemiri- } \\
\text { ngan Hand- } \\
\text { phone }\end{array}$} & \multicolumn{2}{|c|}{$\begin{array}{l}\text { Refe- } \\
\text { rensi }\end{array}$} & \multicolumn{2}{|c|}{ Aktual } & \multicolumn{2}{|c|}{ Error } \\
\hline & & $\mathbf{x}$ & $y$ & $\mathbf{x}$ & $y$ & $\mathbf{x}$ & $y$ \\
\hline Maiu & $\begin{array}{c}\text { Mene-ngadah ke } \\
\text { denan } \pm 30^{\circ}\end{array}$ & 0 & -18 & 0 & -18.4 & 0 & 0.4 \\
\hline $\begin{array}{l}\text { Mun- } \\
\text { dur }\end{array}$ & $\begin{array}{c}\text { Mene-ngadah ke } \\
\text { belakang } 230^{\circ}\end{array}$ & 0 & 19 & 0 & 19.4 & 0 & 0.4 \\
\hline $\begin{array}{l}\text { Maiu } \\
\text { Kiri }\end{array}$ & $\begin{array}{l}\text { Miring ke kirit } \pm \\
30^{\circ}\end{array}$ & 16 & 0 & $\begin{array}{c}16 . \\
3\end{array}$ & 0 & 0.3 & 0 \\
\hline $\begin{array}{c}\text { Maiu } \\
\text { Ka-nan }\end{array}$ & $\begin{array}{c}\text { Miring ke kanan } \\
\pm 30^{\circ}\end{array}$ & .10 & 0 & 10. & 0 & 0.4 & 0 \\
\hline $\begin{array}{l}\text { Mun- } \\
\text { dur Kiri }\end{array}$ & $\begin{array}{l}\text { Miring diagonal } \\
\text { kekanan } \pm 30^{\circ}\end{array}$ & .12 & 8 & $\begin{array}{c}\cdot \\
12 . \\
4\end{array}$ & 8.5 & 0.4 & 0.5 \\
\hline $\begin{array}{l}\text { Mun- } \\
\text { dur Ka- } \\
\text { nan }\end{array}$ & $\begin{array}{c}\text { Miring diagonal } \\
\text { kekird } \pm 30^{\circ}\end{array}$ & 9 & 8 & 9.5 & 8.4 & 0.5 & 0.4 \\
\hline \multicolumn{6}{|c|}{ Rata-Rata Error } & 0.27 & 0.28 \\
\hline
\end{tabular}

Dari percobaan yang telah dilakukan, dapat dilihat bahwa dalam 6 kali percobaan, rata-rata eror pada pergerakan sumbu $x$ adalah sebesar $0.27 \mathrm{~cm}$ sedangkan rata-rata eror pada pergerakan sumbu y adalah sebesar $0.28 \mathrm{~cm}$.

\section{PENUTUP}

Penelitian ini membuat mobile robot dimana sistem navigasinya menggunakan aplikasi android pada smartphone. Komunikasi antara smartphone dengan robot menggunakan komunikasi bluetooth menggunakan baudrate 57600 bps.

Robot akan bergerak pada koordinat tertentu sesuai dengan koordinat yang dikirim dari smartphone. Dari pengujian yang dilakukan rata-rata eror yang telah terjadi selama pergerakan pada sumbu x adalah $0.27 \mathrm{~cm}$ sedangkan pada sumbu y adalah $0.28 \mathrm{~cm}$. Dapat disimpulkan bahwa mekanisme sistem navigasi menggunakan aplikasi android pada smartphone cukup baik digunakan untuk pergerakan mobile robot dalam mencapai titik koordinat tertentu.

\section{UCAPAN TERIMA KASIH}

Ucapan terima kasih penulis sampaikan kepada Universitas Widya Kartika yang telah menyediakan fasilitas Laboratorium Teknik Elektro untuk melakukan penelitian ini.

\section{REFERENSI}

[1] Lewenusa, Ivan. Wisnu Ananta Kusuma. 2008. "Autonomous Mobile Robot Menggunakan Metode Formal Logika Temporal Linier", Seminar Nasional Informatika. Pages:145 - 152.

[2] Yulianto, Andik. Edy Ramadan. 2014. Sistem Kendali Robot Manipulator Pemindah Barang dengan Umpan Balik Visual. Jurnal Ilmiah Mikrotek. 1(2):1-8

[3] Kartowisastro, Iman H. 2008. Bipedal Walking Robot. Jurnal Teknik Komputer. 18(2):109-122

[4] Umam, Faikul. 2013. Pengembangan Sistem Kendali Pergerakan Autonomous Mobile Robot Untuk Mendapatkan Jalur Bebas Hambatan Menggunakan Fuzzy Logic Controller. Jurnal Ilmiah Mikrotek. 1(1):3542

[5] Kristiyana, Samuel. 2008. Desain Dan Sistem Pengendalian Robot Beroda Pemadam Api. Jurnal Teknologi. 1(1):14-23

[6] Saputra, Andi. Dwi Febriansyah. Haris Kuswara. 2014. Alat Kendali Lampu Rumah Menggunakan Bluetooth Berbasis Android. Jurnal Teknologi dan Informatika. 4(1):273286

[7] Anwar, Yogie El, Noer Soedjarwanto. Ageng Sadnowo Repelianto. 2015. Prototype Penggerak Pintu Pagar Otomatis Berbasis Arduino Uno ATMEGA 328P dengan Sensor Sidik Jari. Jurnal Rekayasa dan Teknologi Elektro. 9(1):30-41

[8] Putra, Bram Anggita. Djoko Untoro Suwarno. 2016. Sistem Akuisisi Data Pemakaian Bahan Bakar dan Jarak Yang Ditempuh Berbasis Arduino. Jurnal Ilmiah Widya Teknik. 15(1):1 